\title{
On the aggregate effects of immigration in Spain
}

\author{
Mario Izquierdo • Juan F. Jimeno • Juan A. Rojas
}

Received: 2 October 2008 / Accepted: 1 February 2010 / Published online: 11 March 2010

(C) The Author(s) 2010. This article is published with open access at Springerlink.com

\begin{abstract}
Over the period 1995-2006 the Spanish economy experienced a rapid increase in employment and output growth, a surge in investment over GDP, a substantial deterioration in the current account balance and an improvement in the finances of the social security system. This paper presents a dynamic general equilibrium model designed to quantify the role played by immigration in shaping these facts. In the context of the aging of the Spanish population, we also analyze the medium and long run effects of the immigration process accounting for relevant supply and demand effects. This is done by allowing for enough heterogeneity in the demographic characteristics of immigrant and native workers in a way that allow us to perform counterfactual experiments regarding the flow of immigrants and its skill composition.
\end{abstract}

Keywords Overlapping generations · Immigration

JEL Classification $\quad \mathrm{E} 20 \cdot \mathrm{J} 10$

We are grateful to Fransesc Ortega and seminar participants at INSIDE and the Workshop "Modelling the effects of pensions and other welfare state transfers in an aging world" organized by the Institute for Fiscal Studies (Spain) for helpful comments. The views expressed in this paper are solely those of the authors and do not reflect those of the Bank of Spain or the Eurosystem.

M. Izquierdo

Banco de España, Calle Alcala 48, 28014 Madrid, Spain

J. F. Jimeno

Banco de España, CEPR and IZA, Madrid, Spain

J. A. Rojas ( $\varangle)$

División de Investigación, Banco de España, Calle Alcala 48, 28014 Madrid, Spain

e-mail: juan.rojas@bde.es 


\section{Introduction}

Immigration flows into Western Europe accelerated since the early 1990s. There is a significant body of empirical literature regarding the impact of immigration on the host country, but most of it refer to Anglo-Saxon countries. Since there are reasons to believe that the effects of immigration may vary across countries, depending upon the demographic characteristics of the immigrants and of the native workers and the functioning of the labour market, the demand for economic analysis and empirical evidence on the economic effects of immigration in other recipient countries has significantly increased.

Broadly speaking, the quantitative studies of the impact of immigration on the host country can be grouped into two categories: (i) microeconometric studies of the impact of immigrants on the labour market performance of the native workers, and (ii) macroeconomic studies based on the calibration of some general equilibrium models that, typically, incorporate some parameters estimated by microeconometric studies. ${ }^{1}$ Two examples of this second category are Canova and Ravn (2000) and Storesletten (2001). Both cases are closed economy frameworks in which all prices are endogenous and consequently the possible impact of immigration on the evolution of the current account cannot be addressed. Since one of our aims is to quantify the role of observed immigration flows in shaping the recent evolution of the current account in Spain, we have to stick to an open economy setup.

Among all Western European countries, Spain, traditionally an out-migration country, has been, by far, the largest recipient of immigrants: foreign population residing in Spain, 0.35 millions (1\% of total population) in 1995, went up to 4.1 millions (around $10 \%$ of total population) in 2006 . This immigration boom has expanded both aggregate supply and aggregate demand and plausibly altered the functioning of the Spanish labour market. ${ }^{2}$ Hence, immigration has probably had significant aggregate effects.

First, there are the demographic effects of immigration. Western European countries are going through a demographic transition with significant population ageing. Although demographic ageing is not a new phenomenon, it has now assumed unprecedented proportions owing to the post-war baby boom, and the baby bust that followed. One extreme case is Spain, where the aging of the baby boom generation and the very low levels of the fertility rates, e.g. 1.17 and 1.2 in 1995 and 2000 respectively, are expected to increase the ratio of the elderly ( 65 and older) over the total population from $16.96 \%$ in 2004 to $35.6 \%$ by $2050 .{ }^{3}$ As the age structure of immigrants is in general younger than that of the host population, there is a popular belief that a more generous immigration policy can increase the working-age population and help to reduce the pension burden of the elderly by 2030-2055 which is when the large cohorts born in the 60 s and 70 s in Spain will be retired.

\footnotetext{
1 Examples of the first category are, for instance, Card (2001), Borjas (1999), and Ottaviano and Peri (2006).

2 Some previous studies on several economic effects of inward migration flows to Spain are Aparicio and Tornos (2000), Collado et al. (2004), Oficina Económica del Presidente (2006) and Catalunya (2006).

3 These figures come from Eurostat Demographic Statistics 1996.
} 
Secondly, there are the effects of immigration on the labour market. These immigration flows, not only imply a huge labour supply shock, also alter the skill composition of the labour force and the functioning of the labour market. For instance, immigrant workers are typically regarded as a production factor that substitutes low skilled native workers, while it is complementary of both physical capital and high skilled native workers. Also, as their bargaining power at wage setting is plausibly lower, their wages, after controlling for observable characteristics, are typically lower.

Thirdly, there are the effects of immigration on productivity and long-run growth. Since the mid-1990s, labor productivity growth has significantly fallen in some European countries and, most noticeably, in Spain. ${ }^{4}$ Since immigrants are typically employed in labour intensive sectors with below average productivity, part of the decline of labour productivity growth is the result of a transitory negative composition effect. However, depending on assimilation patterns of immigrants, the size of future immigration flows and their skill composition, this effect on productivity growth could be more lasting.

The computation of these aggregate effects of immigration ${ }^{5}$ requires the use of a general equilibrium model capable of accounting for all the relevant supply and demand effects of immigration. In this paper we use a large overlapping generations model, calibrated to the Spanish economy, to perform such an exercise. ${ }^{6}$ Given the lack of microeconomic studies on the impact of immigration into Spain, we start from the basic specification of this type of models, trying to achieve sufficient flexibility to enrich the model as more empirical evidence becomes available. In this respect, our approach takes as given the age, fertility and skill characteristics of current immigrants in Spain. We consider an initial steady state characterized by the age structure of the Spanish population in 1995 and study the effects of several immigration scenarios on several macroeconomic variables (GDP, employment, productivity, etc.).

Our main results show that: (i) immigration caused a rise of the employment rate through its impacts on the age structure of the population and on the aggregate participation rates (immigrants were younger and had higher participation rates), (ii) immigration had a significant negative effect on productivity, due mainly to the occupational composition of immigrants' employment, (iii) overall, the effect of immigration on GDP per capita was positive, but not large, (iv) immigration also led to a rise in the aggregate investment rate, while the impact on the saving rate was less significant, and (v) plausible immigration scenarios in the forthcoming years cannot avoid a significant rise in pension expenditures and a noticeable worsening in the financial situation of the Social Security system.

The structure of the paper is standard. Sections 2 and 3 describe, respectively, the model and the calibration strategy; Sect. 4 presents the findings and Sect. 5 contains some concluding remarks and hints at several research lines that could contribute to enrich the model in the future.

\footnotetext{
4 See Jimeno et al. (2006).

5 We abstract from returned migration. See Ortega (2007) for an analysis of the political support for unskilled immigration under permanent and temporary scenarios.

6 Similar approaches are Rojas (2005) and Diaz-Gimenez and Diaz-Saavedra (2009).
} 


\section{The model}

\subsection{Demographics}

The economy is populated by agents that live a maximum of $I$ periods. Each agent is indexed by age $i$, time $t$, type $j$ and native status $n$. The index $n$ represents the age of an individual when entering the country, consequently a native has $n=1$ and an immigrant is indexed by $n \geq 2$. Depending on occupation $j$ they can be more or less productive and we allow for different occupational distributions for natives and immigrants and hence, we define $\omega_{j, n}$ as the probability of having productivity $j$ conditional on being a native $n=1$ or immigrant $n \geq 2$. Upon arrival at the age of $i \geq I_{A}$ an agent starts taking decisions. Each individual is endowed with 1 unit of time that can be allocated to work or leisure up to age $I_{R-1}$. After this age agents retire. Each agent faces an age dependent probability of surviving between age $i$ and age $i+1$ at $t$ denoted by $s_{i, t}$. Then the unconditional probability of reaching age $i$ for an individual that has age $v$ at $t$ is $\pi_{v, t}^{i}=\prod_{k=v+1}^{i} s_{k-1, t+k-v-1}$ with $\pi_{v, t}^{v}=1$.

The population age groups of native individuals within each occupation (which is constant through time), i.e. those with subindex $n=1$ are those who survive from the previous period according to the age specific survival probability specified before,

$$
N_{i+1, t+1, j, n}=s_{i, t} N_{i, t, j, n} \quad \text { if } n=1 .
$$

On the other hand, new immigrants moves according to the following law of motion. Those who just enter the country in a given period are sorted into occupations, represented by the index $j$, according to the probability $\omega_{j, n}$, then

$$
N_{i+1, t+1, j, n}=\omega_{j, n} I N_{i+1, t+1} \text { if } i+1=n
$$

where $I N_{i+1, t+1}$ denotes the number of new immigrants at time $t+1$ with age $i+1$. Once immigrants are in the host country, their age groups evolve according to the survival probability as in the case of natives

$$
N_{i+1, t+1, j, n}=s_{i, t} N_{i, t, j, n} \quad \text { if } i+1>n .
$$

Regardless the native status, all individuals are assumed to reproduce according to an age specific fertility rate represented by $b_{i, t}$. Therefore, individuals in the first age group are the children of all individuals in the economy (immigrants and natives) plus the immigrants that enter the country with age 1 , or equivalently

$$
N_{1, t+1, j, 1}=\omega_{j, 1}\left(\sum_{i} \sum_{j} \sum_{n} N_{i, t, j, n} b_{i, t}+I N_{1, t+1}\right) .
$$

Finally, total population $\mathrm{POP}_{t}$, the share of age- $i$ and type- $j-n$ individuals over the total population at time $t \mu_{i, t, j, n}$ and the gross population growth rate are defined as 
follows:

$$
\begin{gathered}
\mathrm{POP}_{t}=\sum_{i} \sum_{j} \sum_{n} N_{i, t, j, n} \\
\mu_{i, t, j, n}=\frac{N_{i, t, j, n}}{\mathrm{POP}_{t}} \\
1+n p_{t}=\frac{\mathrm{POP}_{t+1}}{\mathrm{POP}_{t}}
\end{gathered}
$$

\subsection{Preferences}

At each point in time agents are assumed to maximize lifetime utility. The problem of the typical agent that at $t$ has age $i=v\left(v \geq I_{A}\right)$ is to choose consumption and leisure $l_{i, t, j, n}=1-h_{i, t, j, n}$ to solve the problem

$$
\operatorname{Max} \sum_{i=v}^{I} \beta^{i-v} \pi_{v, t}^{i} U\left(c_{i, t+i-v, j, n}, h_{i, t+i-v, j, n}\right)
$$

Let define labor income net of taxes as

$$
y_{i, t, j, n}=w_{t} \phi_{i, t, j, n} e_{i, j, n} h_{i, t, j, n}\left(1-\tau_{l, t}-\tau_{s s}\right)
$$

where $e_{i, j, n}$ is the efficiency index, $w_{t}$ is the hourly wage per efficiency unit, $\phi_{i, t, j, n}$ is the age specific employment rate, the social security proportional tax and the proportional labor income tax are respectively $\tau_{s s, t}$ and $\tau_{l, t}$ and $d_{i, t, j, n}$ are the social security benefits. Then, the maximization is subject to the period-by-period budget constraint which in the case of a working household $\left(i<I_{R}\right)$ is

$$
a_{i+1, t+1, j, n}=\left(1+r_{t}\left(1-\tau_{k}\right)\right)\left(a_{i, t, j, n}+B_{t}\right)+y_{i, t, j, n}-c_{i, t, j, n}
$$

and in the case of a retired household $\left(i \geq I_{R}\right)$ is

$$
a_{i+1, t+1, j, n}=\left(1+r_{t}\left(1-\tau_{k}\right)\right)\left(a_{i, t, j, n}+B_{t}\right)+d_{i, t, j, n}-c_{i, t, j, n}
$$

with $a_{1, t, j, n}=0, a_{I+1, t, j, n}=0$. The discount parameter is $\beta$, and is assumed to be the same for all agents. Borrowing is possible and agents accumulate asset holdings to smooth consumption over time. $r_{t}$ is the interest rate net of depreciation, $a_{i+1, t+1, j, n}$ denotes next period asset holdings and $\tau_{k}$ is a proportional capital income tax. Notice that since borrowing is possible, the formulation of the budget constraint implies that government subsidizes interest payments on debt, which is a way to capture the fact that in the Spanish tax code, mortgage interests are tax-deductible. Finally, $B_{t}$ is the accidental bequest received at $t$. 
The specific utility function of the household is

$$
u(c, h)=\frac{c_{i, t, j, n}^{1-\sigma}}{1-\sigma}-\phi_{i, t, j, n} H \frac{h_{i, t, j, n}^{1+\mu}}{1+\mu} .
$$

Notice that we are implicitly assuming that at each point in time only a proportion $\phi_{i, t, j, n}$ of household members are employed, but its members choose consumption and labor (of those who are employed) so as to maximize joint utility under the assumption that employed and non-employed members enjoy the same consumption allocation. In this case, the intertemporal and intratemporal first order conditions of the household are respectively

$$
\begin{aligned}
c_{i, t, j, n}^{-\sigma} & =\beta s_{i, t}\left(1+r_{t}\left(1-\tau_{k}\right)\right) c_{i+1, t+1, j, n}^{-\sigma} \\
H h_{i, t, j, n}^{\mu} & =w_{t} \phi_{i, t, j, n} e_{i, j, n}\left(1-\tau_{l, t}-\tau_{s s}\right) c_{i, t, j, n}^{-\sigma} .
\end{aligned}
$$

\subsection{Production technology}

Production in period $t$ is given by a standard constant returns to scale production function that converts capital $K_{t}$ and labor $N_{t}$ into output. The technology $Z_{t}$ improves over time at a constant rate because of labor augmenting technological change according to $Z_{t+1}=(1+\lambda) Z_{t}$. Competitive firms rent labor and make investment decisions taking into account the existence of adjustment costs to investment

$$
C A D J_{t}=\frac{\chi}{2}\left(\frac{I_{t}}{I_{t-1}}-\gamma_{s s}\right)^{2} I_{t}
$$

These adjustment costs are used among others in Christiano et al. (2005) and Burnside et al. (2004), and are by now standard in dynamic general equilibrium models. These costs penalize large changes in investment, and are typically used in order to dampen the reaction of investment to different shocks. In our set up, these costs have been expressed over the growth rate of the economy in the initial steady state $\gamma_{s s}=(1+$ ג) $\left(1+n p_{s s}\right)$ so that in this initial situation those are zero. To see that, notice that after removing the effect of productivity growth $(1+\lambda)$ and population growth $(1+n p)$, the ratio between this period and the past period investment is $\frac{I_{t}}{I_{t-1}}=\frac{\hat{I}_{t}}{\hat{I}_{t-1}}(1+\lambda)\left(1+n p_{s s}\right)$, and since in the initial steady state $\hat{I}_{t}=\hat{I}_{t-1}$, then $\frac{I_{t}}{I_{t-1}}=(1+\lambda)\left(1+n p_{s s}\right)$.

Firms act so as to maximize the present value of current and future cash flows using the discount factor $\frac{1}{1+r_{j}}$ where $r_{j}$ is the exogenous interest rate. At period $t$ cash flows are given by

$$
D_{t}=F\left(K_{t}, Z_{t} N_{t}\right)-C A D J_{t}-w_{t} N_{t}-I_{t}
$$


Then formally, the problem solved by firms is

$$
\begin{aligned}
& \operatorname{Max} D_{t}+V_{t} \\
& =D_{t}+\sum_{s=t+1}^{\infty}\left(\prod_{j=t+1}^{s} \frac{1}{1+r_{j}}\right)\left[F\left(K_{s}, Z_{S} N_{s}\right)-C A D J_{s}-w_{s} N_{s}-I_{s}\right]
\end{aligned}
$$

subject to

$$
I_{s}=K_{s+1}-(1-\delta) K_{s} \quad \forall s \geq t
$$

The problem's first order conditions with respect to $N_{s}, K_{s+1}$ and $I_{s}, \forall s \geq t$ are respectively

$$
\begin{gathered}
F_{N}^{\prime}\left(K_{s}, Z_{s} N_{s}\right)=w_{s} \\
1+r_{s+1}=\frac{F_{K}\left(K_{s+1}, Z_{s+1} N_{s+1}\right)+q_{s+1}(1-\delta)}{q_{s}} \\
q_{s}+\frac{\chi}{1+r_{s+1}}\left(\frac{I_{s+1}}{I_{s}}\right)^{2}\left(\frac{I_{s+1}}{I_{s}}-\gamma_{s s}\right) \\
=1+\chi\left(\frac{I_{s}}{I_{s-1}}-\gamma_{s s}\right)\left(\frac{I_{s}}{I_{s-1}}\right)+\frac{\chi}{2}\left(\frac{I_{s}}{I_{s-1}}-\gamma_{s s}\right)^{2}
\end{gathered}
$$

\subsection{Government}

The government levies a proportional social security tax on labor income $\tau_{s s, t}$ to finance a benefit $d_{i, t, j, n}$ per retiree

$$
d_{I_{R}, t, j, n}=\max \left(P_{\min }, \min \left(P_{\max }, \frac{r e p}{1+\lambda} w_{a v}\right)\right)
$$

where $\lambda$, rep, $w_{a v}$ and $P_{\max }$ are the productivity growth, the legal replacement rate, some average of past earnings and the maximum pension benefit respectively. From age $I_{R}+1$ to $I$, the pension benefit is normalized by productivity growth $(1+\lambda)$, since new pensions are greater than old ones, i.e. $d_{i, t, j, n}=\frac{d_{i-1, t, j, n}}{1+\lambda}$ 
The government also levies a $\tau_{k}$ and $\tau_{l, t}$ to finance per capita government consumption $G_{t}$ such that

$$
\begin{aligned}
& \sum_{n=1}^{N} \sum_{j=1}^{J} \sum_{i=I_{A}}^{I_{R}-1} \mu_{i, t, j, n} w_{j, t} \phi_{i, t, j, n} h_{i, t, j, n} e_{i, j, n} \tau_{s s, t} \\
& \quad+\sum_{n=1}^{N} \sum_{j=1}^{J} \sum_{i=I_{A}}^{I} \mu_{i, t, j, n}\left(r_{t} a_{i, t, j, n} \tau_{k}+w_{t} \phi_{i, t, j, n} h_{i, t, j, n} e_{i, j, n} \tau_{l, t}\right) \\
& =\sum_{n=1}^{N} \sum_{j=1}^{J} \sum_{i=I_{R}}^{I} \mu_{i, t, j, n} d_{i, t, j, n}+G_{t} .
\end{aligned}
$$

\subsubsection{The equilibrium}

A Competitive Equilibrium is a list of sequences of quantities $c_{i, t, j, n}, h_{i, t, j, n}, a_{i, t, j, n}$, $\mu_{i, t, j, n}, d_{i, t, j, n}, N_{t}, K_{t}$, prices $w_{t}, q_{t}, r_{t}$, social security tax rates $\tau_{s s, t}$ and income tax rates such that, at each point in time $t$ :

1. firms maximize profits

2. agents maximize lifetime utility subject to the period budget constraints taking as given wages, the interest rate, taxes, social security benefits, survival probabilities, the age structure of the population and accidental bequests,

3. the age structure of the population $\left\{\mu_{i, t, j, n}\right\}$ follows the aggregate law of motions

4. accidental bequests are given by

$$
B_{t}=\frac{\sum_{n} \sum_{j} \sum_{i} \mu_{i-1, t-1, j, n} a_{i, t, j, n}\left(1-s_{i-1, t-1, j}\right)}{\left(1+n p_{t-1}\right) \sum_{n} \sum_{j} \sum_{i=I_{A}}^{I} \mu_{i, t, j, n}}
$$

5. Market clearing conditions for labor holds

$$
N_{t}=\sum_{j=1}^{J} \sum_{i=I_{A}}^{I_{R}-1} \sum_{n=1}^{N} \mu_{i, t, j, n} \phi_{i, t, j, n} e_{i, j, n} h_{i, t, j, n}
$$

6. Let aggregate wealth be

$$
A_{t}=\sum_{n=1}^{N} \sum_{j=1}^{J} \sum_{i=I_{A}}^{I} \mu_{i, t, j, n} a_{i, t, j, n}
$$

and $F A_{t}$ be the net foreign asset position, then the following holds

$$
F A_{t+1}=A_{t+1}-V_{t}
$$

where as indicated in the problem of the firm $V_{t}$ refers to the value of the firm, which is equal to the discounted sum of future profits starting on date $t+1$. 
7. the budget constraint of the government is satisfied period by period

8. and the good market clearing condition is satisfied

$$
F\left(K_{t}, Z_{t} N_{t}\right)=C_{t}+I_{t}+C A D J_{t}+G_{t}+F A_{t+1}-\left(1+r_{t}\right) F A_{t}
$$

where the current account is the variation of net foreign assets $\left(C A_{t}=F A_{t+1}-\right.$ $F A_{t}$ ), and the trade balance is the variation of net foreign minus income from these assets $\left(T B_{t}=C A_{t}-r_{t} F A_{t}\right)$.

\section{Calibration}

\subsection{Demographics}

Each model period corresponds to 1 year. Agents reach adulthood at 16 and live up to age 100, after which death is certain. We take the age structure of the population of 1995 as the initial condition in order to propagate the population to the future. In that year, the stock of immigrants represented $1 \%$ of the total population. This number and the fact that there is no data set available in order to know when existing immigrants entered the country, lead us to make no distinction between immigrants and natives in the initial steady state. In order to obtain the initial asset distribution we are implicitly assuming that individuals living in the initial steady state think that the population will not change.

After 1995, given the dynamics of fertility and the mortality, we propagate the age structure of the population until it becomes stationary (in the sense that the share of each age group over the total population does not change through time) under several scenarios about the immigration flows. ${ }^{7}$

\subsubsection{Immigration flows}

Our baseline scenario takes the reported number of new immigrants in the Labour Force Survey (Encuesta de Poblacion Activa) which increases from 33,060 in 1996 to 507,500 in 2005, and from 2006 to 2050 the number of inflows decreases until it settles around 270,000 immigrants per year. ${ }^{8}$ The age distribution of these migration flows are taken to be constant and are computed as follows. The available data refers only to age groups of 10 years, and almost $80 \%$ of the new immigrants enter the country with less than 40 years of age. Since in our model a period is 1 year, for computational reasons, we have assumed that there are 40 possible ages at which immigrants can enter the country. Furthermore, the proportion of new immigrants to each age group has been obtained by fitting a second order polynomial to the current age distribution of new immigrants in Spain (see first panel of Fig. 1). Finally, these immigrants are assumed to have the same mortality and fertility rate as natives.

\footnotetext{
${ }^{7}$ Fertility and mortality rates are obtained from the demographic projections (scenario 1) of the Instituto Nacional de Estadística.

8 These figures are contemplated in the high-immigration scenario of the most recent demographics forecast of the Spanish National Statistics Office.
} 


\subsubsection{Heterogeneity}

In order to properly account for the potential differences in productivity between natives and immigrants and make alternative experiments concerning the skills content of immigration flows, we have partitioned individuals of the same generation into four possible occupations (qualified non-manual, non-qualified non-manual, qualified manual and non-qualified manual). The distribution of natives and immigrants workers by these occupational levels comes from the Structural Earnings Survey (SES) in 2002, since information about the nationality of the worker was not available in the 1995 wave of this survey. However, according to the information available in the Spanish Labour Force Survey (LFS), the distribution by occupation of immigrant workers has remained roughly constant over this period. As can be seen in Fig. 1, it is important to take into account differences in the occupational distribution of workers by nationality given that immigrants are more concentrated than natives in low-skilled occupations. We assume that new immigrants entering the country until 2050 maintain this occupational distribution.

a

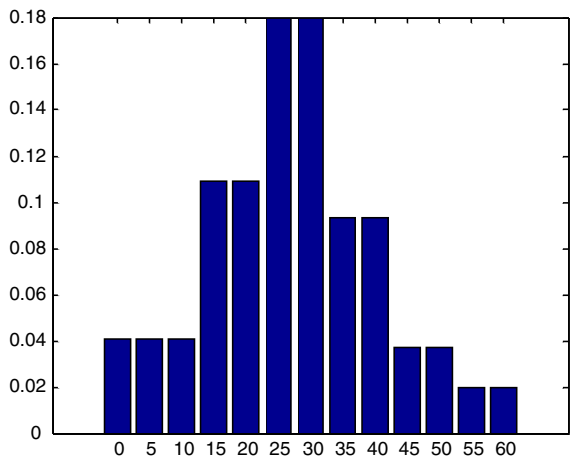

C

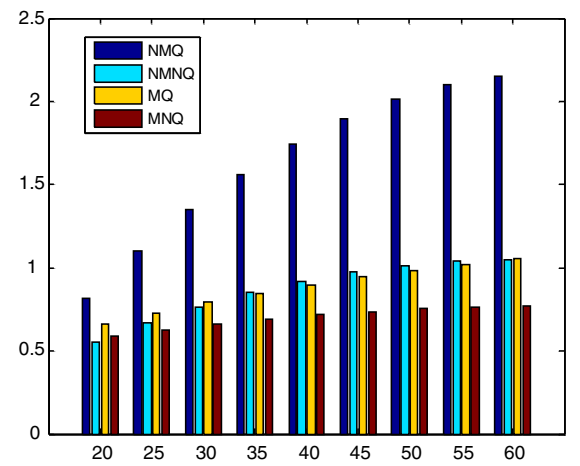

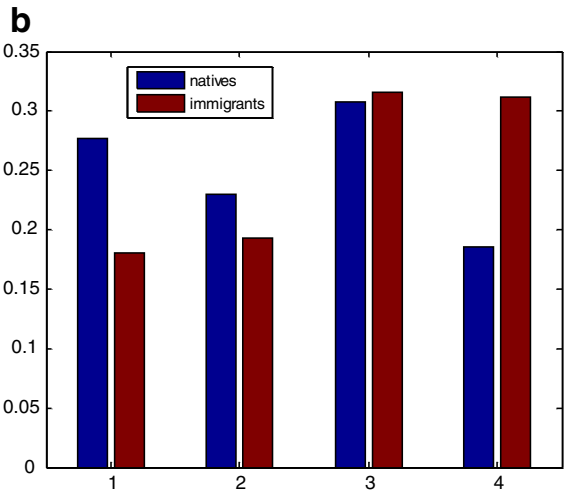

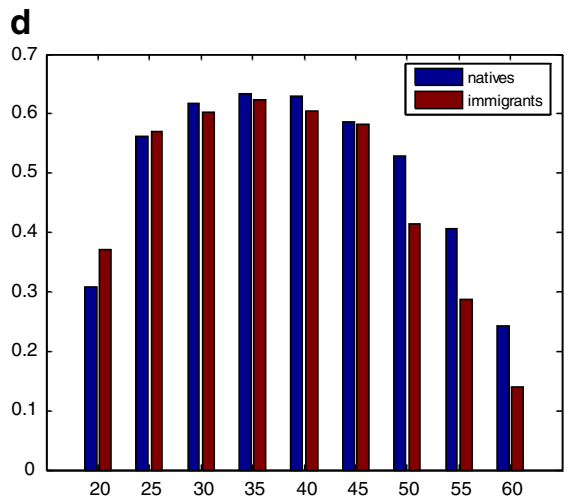

Fig. 1 a Age distribution of immigration flows. b Occupation distribution. c Age distribution of productivity natives. d Age profile of employment rates 
Regarding productivity, we allow productivity differentials across age, nationality and occupational level. As the information about productivity at the individual level is not available, we proxy productivity differentials by wage differentials using, as previously, information from SES in 2002. We compute hourly wages by age groups, nationality and occupational level (see Fig. 1). It should be noticed that in the highest occupational level we assume that the wage differential is zero between natives and immigrants. 9

Finally, individuals, natives and immigrants, are assumed to get employed with a probability equal to the employment rate of their age group. On average, immigrants present a higher employment rate than natives but this gap is mainly due to they are younger, so it is important to take into account age differences. Indeed, as can be seen in Fig. 1, immigrants show slightly lower employment rate for each age group except those less than 25 years. Employment rates are computed using Labour Force Survey data for 2005. We use more recent information for employment rates in order to take into account that new immigrants entering Spain since 1995 have showed higher employment rates than the few immigrants who where already here at that date. We think this is more adequate in order to extrapolate employment rates for new immigrants until 2050.

\subsection{Preferences, production and the world interest rate}

As mentioned before the period utility function of the household is

$$
u(c, h)=\frac{c_{i, t, j, n}^{1-\sigma}}{1-\sigma}-\phi_{i, t, j, n} H \frac{h_{i, t, j, n}^{1+\mu}}{1+\mu}
$$

where the inverse of the elasticity of substitution $\sigma$ is 1.5 . The parameters $\mu$ and $H$ has been set such that the average time spent working is around $1 / 3$ and the Frisch elasticity of labor $(1 / \mu)$ is 0.4 . Hence we use $H=500$ and $\mu=2.5$.

The production technology is Cobb-Douglas

$$
Y_{t}=F\left(K_{t}, Z_{t} N_{t}\right)=K_{t}^{\alpha}\left(Z_{t} N_{t}\right)^{1-\alpha}
$$

and the capital share parameter is $\alpha=0.375$ following the estimates of Diaz-Gimenez and Diaz-Saavedra (2009) for the Spanish economy. The productivity growth has been set to $\lambda=1 \%$ in annual terms which is the average growth of per-capita consumption over the period 1960-1995. The adjustment cost parameter is consistent with the estimates of Christiano et al. (2005) and is equal to $\chi=3$.

Finally, the depreciation rate of capital $\delta$, the international real interest rate and the discount factor parameter $\beta$ are chosen simultaneously to reproduce the following three targets in 1995: (1) An average ratio of gross investment over output I/Y=21.7\%, (2) a ratio of foreign assets over GDP of around $-20 \%$ and (3) a capital output ratio

\footnotetext{
9 Since there are very few observations of immigrants in this occupational level, available data give implausible estimates of wage differentials.
} 
Table 1 Current account in the model versus Spain

\begin{tabular}{lll}
\hline & Data 1995 & Model 1995 \\
\hline Current account/GDP (\%) & -0.3 & -0.44 \\
Net foreign assets/GDP $(\%)$ & -20 & -20 \\
\hline
\end{tabular}

of 2.9. The value of the parameters that satisfies these conditions are $\delta=5.5 \%$, $\beta=0.9983$ and $r=7.7 \%$. It should be noted that in the initial steady state of the model economy the current account deficit over GDP ratio is slightly more negative that the one observed in the data, due to the fact that the model is assumed to be in a steady state, while this is not necessarily the case in the data (Table 1).

\subsection{Government}

Pension benefits are as follows. Upon retirement an individual's pension is computed applying a replacement rate over the average of earnings of the last 15 years before retirement. This replacement rate is, $0 \%$ if an individual has been contributing for less than 15 years, $100 \%$ if he has contributed for at least 35 years, and $60+2(m-15)$ in percent terms if the individual has contributed at least 15 years but less than 35 , where $m$ is the number of contributed years (Table 2). The pension system in Spain also includes a maximum and a minimum pension level equal to 1.85 and 0.44 times the per-capita output in the Spanish economy in 1995. However in the model economy these limits were not binding, due to the fact that we have considered broad qualification's categories. The social security contribution rate is set by computing total

Table 2 Calibration

\begin{tabular}{ll}
\hline Parameters & Targets (1995) \\
\hline $\begin{array}{l}\sigma=1.5 \\
\mu=2.5\end{array}$ & Kotlikoff's estimation \\
$H=500$ & Frisch elasticity around 0.4 \\
$\phi_{i, t, k, n}($ see Fig. 1) & $1 / 3$ of the time working \\
$\alpha=0.375$ & Age profile of employment rates in Spain \\
$\lambda=1 \%$ & Diaz-Gimenez and Diaz-Saavedra (2009) \\
$\chi=3$ & Average growth rate $\%$ consumption \\
$\mathrm{r}=7.7 \%$ & Christiano et al. (2005) estimate \\
$\beta=0.9983$ & FA/GDP $=-20 \%$ in 1995 \\
$\delta=5.5 \%$ & K/Y $=2.9$ in 1995 \\
$G=0.18 * G D P$ & I/GDP $=21.7 \%$ in 1995 \\
$\tau_{k}=0.186$ & Government consumption in 1995 \\
$\tau_{S S}=17.87 \%$ & Bosca et al. (1999) \\
& Ratio of social security contributions \\
rep $=0$ if $n<15$ & over labor income \\
rep $=60+20(n-15)$ & Pension rules in Spain \\
if $35>n>15$ & \\
rep $=100$ if $n>35$ & \\
\hline
\end{tabular}


contributions to the system (which amounted to 39,050.02 millions of euros in 1995) as percentage of labor income in 1995 (218,493 millions of euros), and yields $17.87 \%$. Notice that we are not imposing (as many papers do) the social security system to be balanced. We use a value of the capital income tax $\tau_{k}=0.186$ as reported by Bosca et al. (1999) and set a government to output ratio of $G / Y=18 \%$ which is the ratio of government consumption to GDP in 1995 in Spain. The labor tax rate $\tau_{l, t}$ is set endogenously to balance the overall (including the social security system) government budget. In the initial steady state the value that satisfies this condition is $22.04 \%$. It should be noted that the labor tax will be changing over time as a result of (among other things) possible imbalances between social security contributions and expenditures. In the initial steady state, the above rules generate a ratio of pension expenditure and social security surplus over GDP of 10.6 and $0.45 \%$.

\subsection{Computation method}

The computational procedure used to solve for the transitional dynamics of the model follows Auerbach and Kotlikoff (1987). Notice that since the economy undergoes a transition in which conditions change over time and economic agents are assumed to take into account future prices in determining their behavior, it is necessary to solve simultaneously for the equilibrium in all transition years. In order to implement the computational procedure we assume that the final steady state is reached in 1000 model periods, and have checked that it was not binding. The main steps of the algorithm are the following.

A. Given initial conditions $K_{1}$ and $\left\{\left\{a_{i, t, j, n}\right\}_{i=I_{A}}^{I}\right\}_{t=1}$ and the exogenous sequence of the the age structure of the population $\left\{\mu_{i, t, j, n}\right\}$ and the interest rate $\left\{r_{t}\right\}_{t=1}^{t=1000}$, provide a guess for the path of the price $\left\{q_{t}\right\}_{t=1}^{t=1000}$, future investment $\left\{I_{t+1}\right\}_{t=1}^{t=999}$ and the age profile of work effort $\left\{\left\{h_{i, t, j, n}\right\}_{i=I_{A}}^{I r-1}\right\}_{t=1}^{t=1000} \forall j$, $n$. Then proceed as follows:

- Using $\left\{\left\{h_{i, t, j, n}\right\}_{i=I_{A}}^{I r-1}\right\}_{t=1}^{t=1000}$ compute aggregate labor $\left\{N_{t}\right\}_{t=1}^{t=1000}$

- Using Eq. (21), compute a new sequence of current investment decisions $\left\{I_{t}\right\}_{t=1}^{t=999}$ given past and the guessed future investment decisions

- Then use the law of motion (18) to compute a sequence of next period capitals $\left\{K_{t+1}\right\}_{t=1}^{t=999}$.

- Using $\left\{K_{t}\right\}_{t=1}^{t=1000},\left\{N_{t}\right\}_{t=1}^{t=1000}$ and the marginal productivity condition (19), compute wages $\left\{w_{t}\right\}_{t=1}^{t=1000}$

- Using $\left\{\left\{h_{i, t, j, n}\right\}_{i=I_{A}}^{I r-1}\right\}_{t=1}^{t=1000} \forall j, n$. and wages $\left\{w_{t}\right\}$, compute pension benefits to which agents qualify $\left\{\left\{d_{i, t, j, n}\right\}_{i=I_{R}}^{I}\right\}_{t=1}^{t=1000}$

- Using the arbitrage condition (20), obtain a new sequence of $\left\{q_{t}\right\}_{t=1}^{t=1000}$

- Using the inter-temporal first order conditions of households (13), its budget constraints, the path for the interest rate, wages, transfers, and labor efforts $\left\{\left\{h_{i, t, j, n}\right\}_{i=I_{A}}^{I r-1}\right\}_{t=1}^{t=1000}$, solve for optimal consumption $\left\{c_{i, t, j, n}\right\}_{t=1}^{t=1000} \forall i, j, n$ and asset holdings $\left\{a_{i+1, t+1, j, n}\right\}_{t=1}^{t=999} \forall i, j, n$. 
- Use the computed sequence $\left\{c_{i, t, j, n}\right\}_{t=1}^{t=1000} \forall i, j, n$ and the intra-temporal first order condition of the household problem (14) to compute a new guess of the age profile of work effort $\left\{\left\{h_{i, t, j, n}\right\}_{i=I_{A}}^{I r-1}\right\}_{t=1}^{t=1000}$.

B. If the new sequences, $\left\{q_{t}\right\}_{t=1}^{t=1000},\left\{I_{t}\right\}_{t=1}^{t=1000}$ and $\left\{\left\{h_{i, t, j, n}\right\}_{i=I_{A}}^{I r-1}\right\}_{t=1}^{t=1000}$ are equal to the guesses of step (A) the algorithm is stopped. If not, update the guesses and go back to step (A).

\section{Findings}

In order to analyze the aggregate effects of immigration, we compute the evolution of macroeconomic variables under several scenarios that vary in respect to the size and composition of the immigration flows. We start computing a baseline scenario characterized by two main features: (i) the population ages according to the demographic projections specified in the calibration, including the current immigration flows, and (ii) there is a fall in the international interest rate. In particular we assume that between 1995 and 2005 real interest rate falls by $1.5 \%$ points, as observed in the Spanish economy during this period, and then increases until reaching a level consistent with a long term decline of $1 \%$ point. This expected long-term decline in the real interest rate is consistent with results from recent papers that have addressed the impact of demographics on the evolution of international real interest rate. ${ }^{10}$ Since the model is calibrated for 1995 and, in the baseline scenario we use factual immigration flows for the period 1996-2005, from comparison with observed data we can evaluate to what extent the model is able to predict the impact of immigration over the short-run. In addition, to disentangle the aggregate effects of immigration from the effects of the change in the interest rate, we consider four alternative scenarios combining different paths for immigration flows an the real interest rate. In particular, we have computed five alternative cases:

- Scenario 1 (baseline): Observed immigration flows and a fall in the international interest rate

- Scenario 2: No immigration and a fall in the interest rate

- Scenario 3: No immigration and a constant interest rate

- Scenario 4: An increase in immigration of unskilled workers and a fall in the interest rate

- Scenario 5: Immigration flows as in the baseline scenario, more skilled immigrants and a fall in the interest rate.

\subsection{The aggregate effects of observed immigration flows}

In order to gauge the aggregate effects of immigration flows into the Spanish economy, we present the results of the baseline scenario in comparison to the case of no migration flows (Scenarios 1 and 2). To present the results we use several graphs, plotting the evolution of some labor market variables (wages, employment, and labor supply),

$\overline{10}$ See, for instance, Kara and von Thadden (2006) and Krueger and Ludwig (2006). 
Table 3 Comparing the model and the data

\begin{tabular}{lcccccc}
\hline & \multicolumn{3}{l}{ Data (\%) } & & \multicolumn{2}{l}{ Model (\%) } \\
\cline { 5 - 6 } & & & & Immigration & No immigration \\
\cline { 2 - 3 } \cline { 5 - 6 } & 1995 & 2005 & & 1995 & 2005 & 2005 \\
\hline Current Acc./GDP & -0.33 & -7.4 & & -0.44 & -6.9 & -2.85 \\
Investment/GDP & 21.8 & 29.53 & & 21.6 & 29.59 & 25.41 \\
Pensions/GDP & 8.54 & 7.82 & & 10.6 & 10.1 & 11.09 \\
\hline & $2000-2005$ & & & $2000-2005$ & $2000-2005$ \\
\hline \% GDP growth & 2.11 & & 2.22 & & 2.18 \\
\% Employment growth & 1.70 & & 1.03 & & 0.26 \\
Productivity growth & 0.40 & & 1.17 & & 1.92 \\
\hline
\end{tabular}

Table 4 Results

\begin{tabular}{|c|c|c|c|c|c|}
\hline & $\begin{array}{l}\text { Scenario } 1 \\
{[1]}\end{array}$ & $\begin{array}{l}\text { Scenario } 2 \\
{[2]}\end{array}$ & $\begin{array}{l}\text { Scenario } 3 \\
{[3]}\end{array}$ & $\begin{array}{l}\text { Scenario } 4 \\
{[4]}\end{array}$ & $\begin{array}{l}\text { Scenario } 5 \\
{[5]}\end{array}$ \\
\hline \multicolumn{6}{|c|}{ Employment per capita (\%) } \\
\hline 1995 & 31.99 & 31.99 & 31.99 & 31.99 & 31.99 \\
\hline 2005 & 35.22 & 33.39 & 33.39 & 35.25 & 35.22 \\
\hline 2020 & 35.83 & 30.79 & 30.79 & 37.69 & 35.83 \\
\hline 2050 & 31.64 & 24.99 & 24.99 & 35.59 & 31.64 \\
\hline \multicolumn{6}{|c|}{ GDP per employee (detrended) } \\
\hline 1995 & 53.04 & 53.04 & 53.04 & 53.04 & 53.04 \\
\hline 2005 & 53.86 & 56.60 & 54.52 & 54.05 & 55.45 \\
\hline 2020 & 54.47 & 60.17 & 55.68 & 52.62 & 60.58 \\
\hline 2050 & 51.30 & 56.58 & 53.04 & 48.84 & 60.47 \\
\hline \multicolumn{6}{|c|}{ GDP per capita (detrended) } \\
\hline 1995 & 16.97 & 16.97 & 16.97 & 16.97 & 16.97 \\
\hline 2005 & 18.97 & 18.90 & 18.21 & 19.05 & 19.53 \\
\hline 2020 & 19.52 & 18.53 & 17.14 & 19.83 & 21.71 \\
\hline 2050 & 16.23 & 14.14 & 13.25 & 17.38 & 19.13 \\
\hline \multicolumn{6}{|c|}{ Investment/GDP (\%) } \\
\hline 1995 & 21.56 & 21.56 & 21.56 & 21.56 & 21.56 \\
\hline 2005 & 29.60 & 25.42 & 19.68 & 30.86 & 31.12 \\
\hline 2020 & 20.56 & 16.61 & 15.22 & 23.37 & 22.07 \\
\hline 2050 & 21.11 & 18.49 & 16.45 & 22.78 & 20.70 \\
\hline
\end{tabular}

some macroeconomic variables (the capital labor-ratio, GDP per capita, investment and saving rates, and the current account balance-bcc-), and some variables reflecting the situation of the pension system (the dependency ratio-the ratio of retirees to the labor force-, pensions expenditures, and the Social Security deficit). ${ }^{11}$ We evaluate the short-run performance of the model by comparing the results for 2005 with the observed data (Table 3), and the medium term results for some selected years which are reported in Table 4. For this case the results are in Figs. 2 and 3.

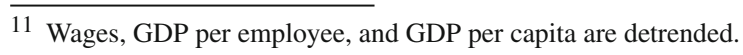



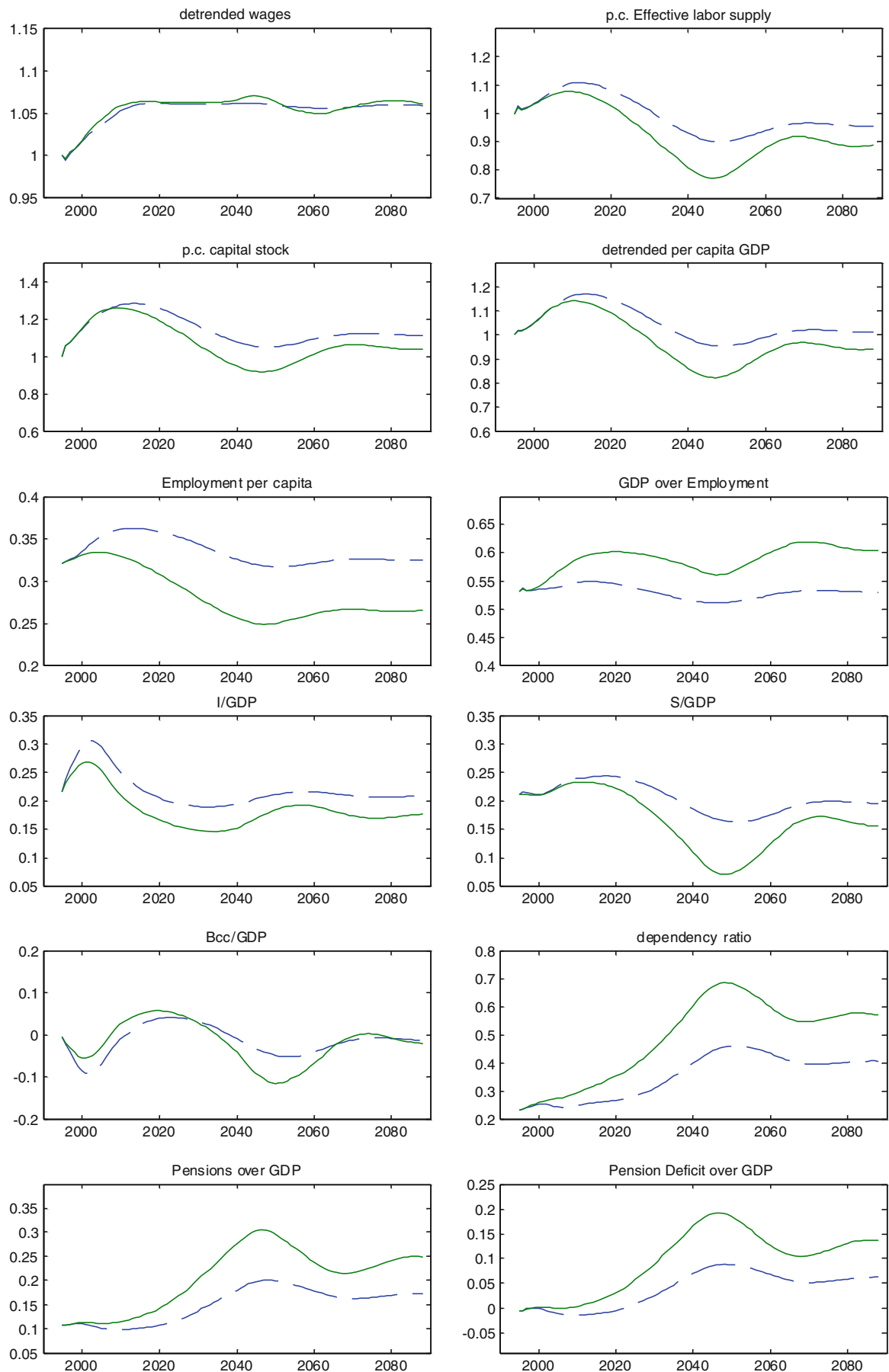

Fig. 2 Dashed lines: Scenario 1, solid lines: Scenario 2 

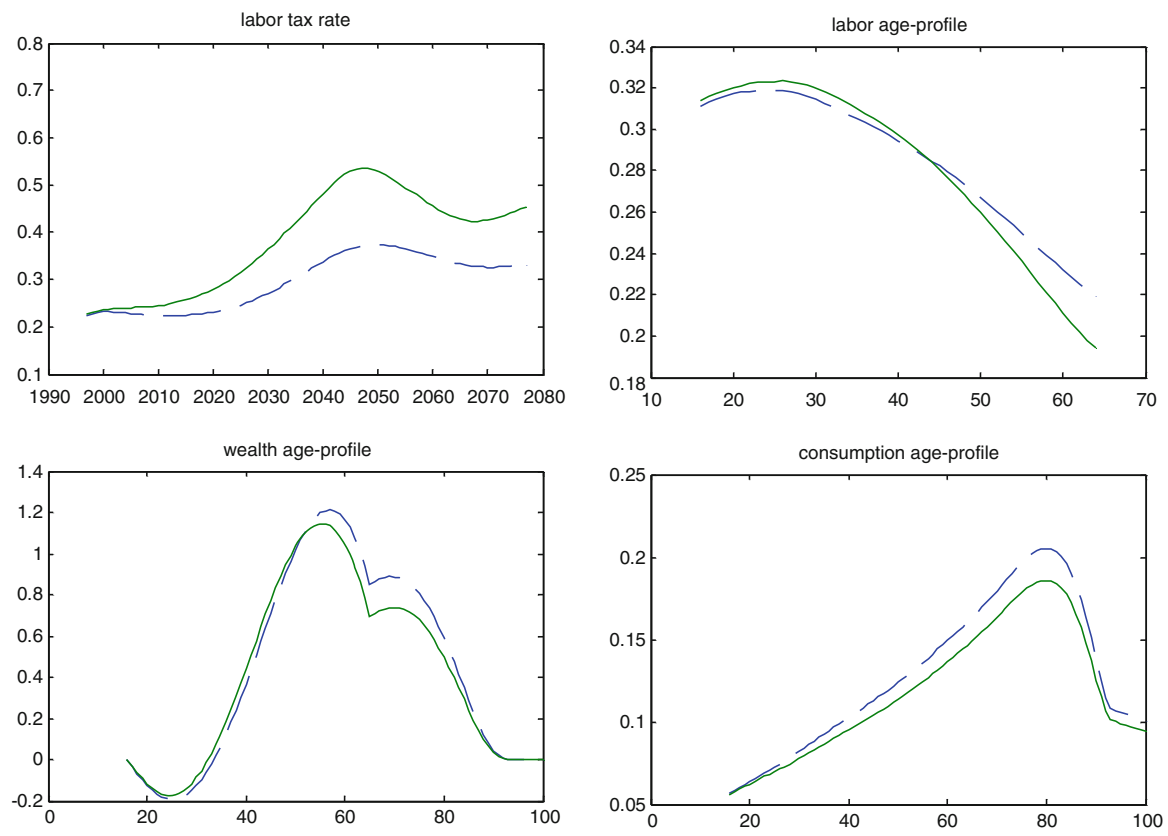

Fig. 3 Taxes and life-cycle behaviour of natives. Dashed lines: Scenario 1, solid lines: Scenario 2 (no immigration)

In the short term, the findings are the following. Immigration contributed both to the rise in employment per capita and to the decline of labor productivity (measured as GDP over employment). Both effects tend to cancel out and, as a result, GDP per capita turns out to be very similar in both scenarios over the initial periods of the transition, although it increases with immigration afterwards. Overall, the model replicates quite well the evolution of GDP per capita, whose average annual rate of growth over the 2000-2005 has been $2.11 \%$ (2.2\% in the model under the baseline [1]). Admittedly, over this period the model produces a lower rate of growth of employment per capita $(1.03 \%$ annual) and a higher rate of growth of labour productivity (1.17\% annual) than observed ( 1.70 and $0.40 \%$, respectively).

Another front where the model comes very close to replicate the observed data over this period is regarding the evolution of investment: the investment rate increased from $21.8 \%$ in 1995 to $29.53 \%$ in the data while in the model economy it increased from $21.6 \%$ of GDP to $29.59 \%$. In fact, the investment rate is substantially higher in the experiment with immigration flows as compared to the case without immigration. The reason is that, with immigration, the lower capital labor ratio increases the marginal productivity of capital and increases the profitability of investment decisions. As a by product of these trends, and having into account that over the short term there is not much difference between both scenarios in terms of the behavior of the saving rate, the model with immigration flows deliver an evolution of the current account deficit as percentage of GDP which is more in line with the data, as compared to the no-immigration scenario. In addition, the model with immigration is able to account for the reduction in the percentage of GDP spent on pensions (Table 3). 
From the comparison between the first two scenarios in the medium term, we draw the following conclusions. Without immigration flows (Scenario 2), the aging of the baby boom generation increases more substantially the number of the retirees over the total population inducing an more pronounced increase in the labor tax rate in order to balance the government budget. In addition, although over the initial periods there is some reduction in the percentage of GDP spent on pensions and the social security deficit in the scenario with immigration flows, this does not impede that both pension expenditures and the Social Security deficit surges to much higher levels that the current ones. However, the inflow of immigrants alleviates, to some extent, the effects of the aging of the baby-boom generation and generates substantial differences in terms of the distortionary effects of taxes (see Fig. 3). This different behavior of the labor tax is what induces substantial changes at the individual level. To further understand how immigration affects agents decisions, we have compared the life-cycle behavior of the average native individual that starts taking decisions in 1996 which is the year of the migration shock. It should also be noted, that since the evolution of wages at the aggregate level is fairly similar in the model economies with and without immigration, the most important driver of after-tax earnings at the individual level is the different evolution of the labor tax needed to balance the government budget. In terms of consumption allocations, in Scenario 2 (without immigration) the higher tax rates and the lower life-cycle after-tax earnings implies that native individuals attain a lower level of consumption through the life-cycle. In addition, the higher level of labor taxes that characterizes the scenario without immigration gives native individuals incentives to substitute hours worked when old by labor effort in the early ages of the life-cycle, in an attempt to avoid tax distortions. Hence, in order to attain the desired consumption profile, in the scenario without immigration individuals will work harder when young and save the extra resources to finance consumption when old, which is when the labor taxes are higher. This process is illustrated in Fig. 3.

As for other aggregate effects (see columns [1] and [2] of Table 4), these are specially noticeable in the case of employment per capita (about 2, 5 and 8 pp higher at 2005, 2020 and 2050 in Scenario 1). This is due to two effects: (i) the continuous immigrant flows of the order of those considered in Scenario 1 imply significantly less population ageing than under no migration, and (ii) the weight of immigrants, who have higher employment rates, in the labor force increases. For a similar composition effect, GDP per employee is significantly lower due to immigration, and also the impact accumulates over time. As for GDP per capita, the effect of immigration, as already commented, is minor but increases over time $(0.37,5.3$, and $15 \%$ higher in Scenario 1 in 2005, 2020 and 2050, respectively). Finally, the impact of immigration on the investment rate is significant: about $4 \mathrm{pp}$ higher at the three horizons presented in Table 4 (diminishing over time due to the existence of investment adjustment costs).

\subsection{The combined effects of immigration and of the fall in the interest rate}

Now we compare Scenario 1 to Scenario 3 (characterized by no immigration and a constant interest rate). This comparison, together with the results in the previous section, allows us to draw some conclusions about the interaction between the effects 
of immigration and the fall of the interest rate. The main qualitative difference is, that, under a constant interest rate there is a smaller increase in the stock of capital, due to the higher cost associated with investment. Hence, there is a lower increase in GDP per capita. The increase in the investment rate and the fall in the saving rate over the initial periods of the transition, associated to the fall in the interest rate disappear (Fig. 4), and, consequently, the current account balance displays a surplus in the initial periods of the transition. In terms of the evolution of social security finances, the fall of the interest rate is not very relevant, as the most important factor determining pension expenditures and the Social Security deficit is the dependency ratio, which do not change in the three Scenarios considered so far. More generally, we can gauge quantitatively how important the effect of the postulated variations of the interest rate could be, by looking at columns [2] and [3] of Table 4. The reduction of $1.5 \mathrm{pp}$ of the real interest rate over the 1995-2005 embedded in Scenario 2 does not affect very much to either employment, productivity or GDP per capita over the short-run. However, as accumulation of capital is larger than under Scenario 3, at longer horizons labor productivity and, consequently, GDP per capita rise.

\subsection{The effects of more unskilled immigration}

In this case, we compare the baseline scenario, which is constructed on the observed and predicted flows by the Spanish National Statistics Office, with an alternative scenario in which immigration flows are permanently higher, at the level of 600,000 immigrants per year (Scenario 4). Regarding the skill distribution of these flows we keep that observed under the baseline scenario, i.e. the one observed in the Spanish economy in the recent period. While it is very unlikely that immigration flows of this order of magnitude can be sustained over such a long period of time, this comparison can give us some intuition on how the returns of immigration depend on the size of the flows. In this case, the number of immigrants arriving at Spain over the 20002050 period is twice the number of immigrants than under Scenario [1]. As a result, employment per capita would be higher (only slightly over the short and medium run and more noticeably at the 2050 horizon) but at the cost of a substantial deterioration of labor productivity (see Fig. 5). Still, larger immigration flows would result in an increase of GDP per capita of a small magnitude. With more immigration, the supply of labor increases, and for the reasons explained before, the investment rate would be also higher, without observing any significant change in the saving rate. Consequently, the current account deficit would suffer an additional deterioration. On the benefit side, the dependency ratio increases less importantly since the population ages less quickly, and the expected increase in the percentage of GDP spent on pensions would be less pronounced.

\subsection{The effects of an upgrade in the skill content of immigration}

Finally, we now keep the immigration flows of the baseline scenario but consider an alternative skill distribution more biased towards high skill occupations as shown in Table 5. 

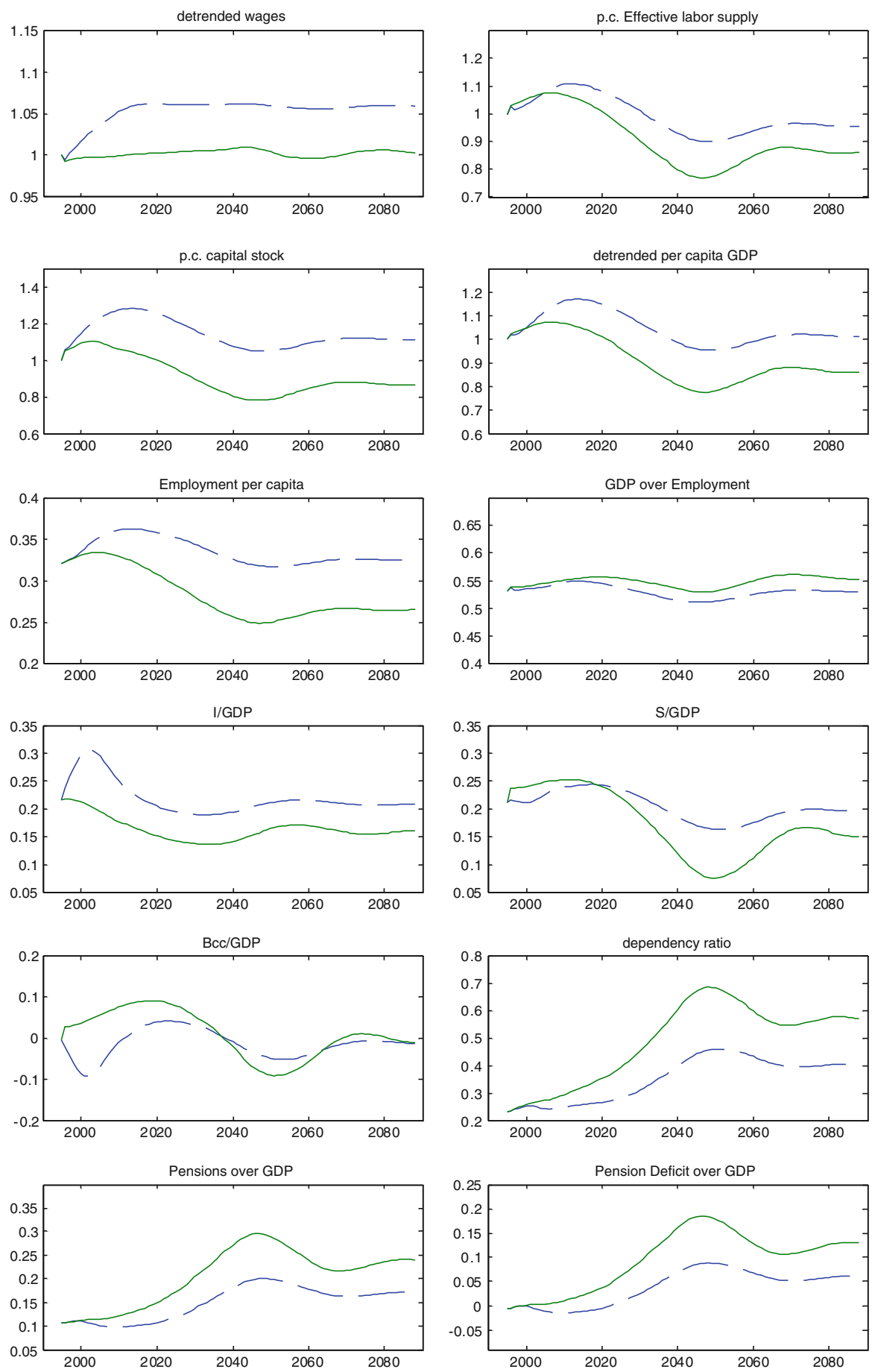

Fig. 4 Dashed lines: Scenario 1, solid lines: Scenario 3 

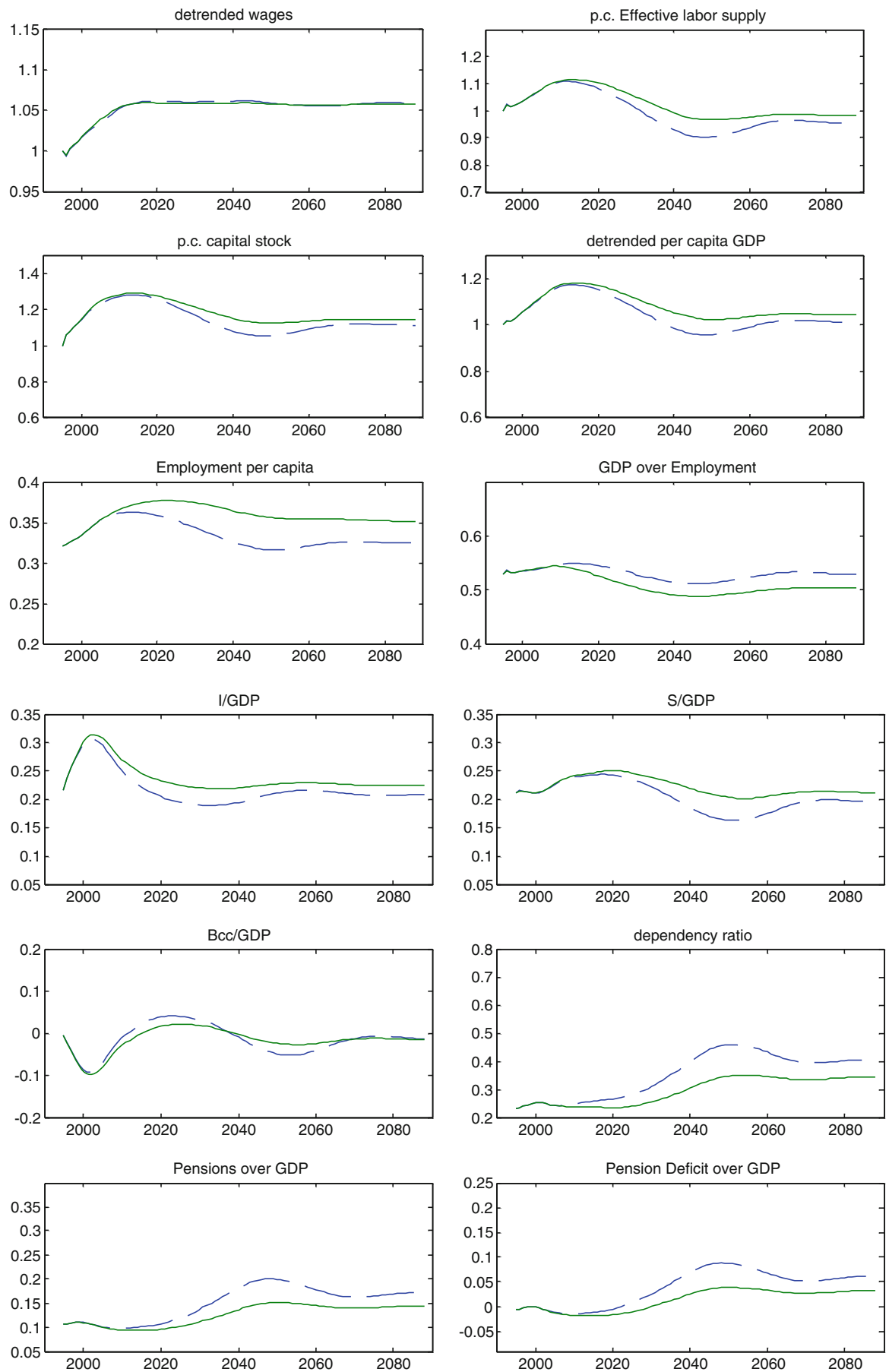

Fig. 5 Dashed lines: Scenario 1, solid lines: Scenario 4 
Table 5 Occupation distribution of immigrants

\begin{tabular}{llllll}
\hline & Non-manual & & & \multicolumn{2}{l}{ Manual } \\
\cline { 2 - 3 } & Skilled (\%) & Unskilled (\%) & & Skilled (\%) & Unskilled (\%) \\
\hline Scenario 1 & 18 & 19.3 & & 31.5 & 31.2 \\
Scenario 5 & 70 & 10 & 10 & 10 \\
\hline
\end{tabular}

As can be seen in Fig. 6 and columns [1] and [5] of Table 4, the most significant effects are to be found in the evolution of GDP per employee. Since in the two scenarios immigration flows are of the same order of magnitude and in our model employment rates of immigrant only vary by age (and not by occupation), the skill upgrade immigration has no effects on employment per capita. However, GDP per capita increases noticeably (by 2.9, 11.2 and 18\%, respectively, at 2005, 2020 and 2050) as a result of a more favorable evolution of labor productivity, which is also impulsed by a larger accumulation of capital.

\section{Concluding remarks}

We have performed several accounting exercises to gauge the aggregate effects of immigration under different conditions, regarding the evolution of interest rates and the skill composition of immigration flows. For that, we have used a dynamic, general equilibrium, overlapping generations model calibrated to the Spanish economy, using as a baseline scenario the demographic projections currently envisaged by the Spanish National Statistics Office. This is a rather stylized model that does not account for several facts, well-documented in microeconometric studies on the effects of immigration in other countries but not yet in Spain, such as different preferences between immigrants and natives regarding the consumption-leisure choice, the imperfect substitution in production between immigrants and natives, the impact of immigrants on the employment rate and productivity of native workers, and the assimilation and return patterns of immigrants. Despite these drawbacks, to be amended as more microeconomic empirical evidence on the Spanish economy becomes available, the results provide some interesting insights on the magnitude of the effects of immigration on employment, productivity, GDP per capita, investment and saving rates, and the financial position of the pension system.

The main conclusions from these exercises are the following. Immigration increases employment through a positive impact on the age structure of the population and a composition effect (coming from higher observed employment rates of the immigrants), but it has a significant negative effect on productivity, so that, overall, its impact on GDP per capita, although positive, is not large. This negative effect on productivity could be avoided with a skill upgrade of the composition of immigrant flows. There are also important effects of immigration on the investment rate, while the impact on the saving rate is less significant. Finally, none of the immigration scenarios contemplated in this exercise, whatever is size or composition, avoid a significant rise in pension expenditures and a noticeable worsening in the financial situation of the Social Security system. 

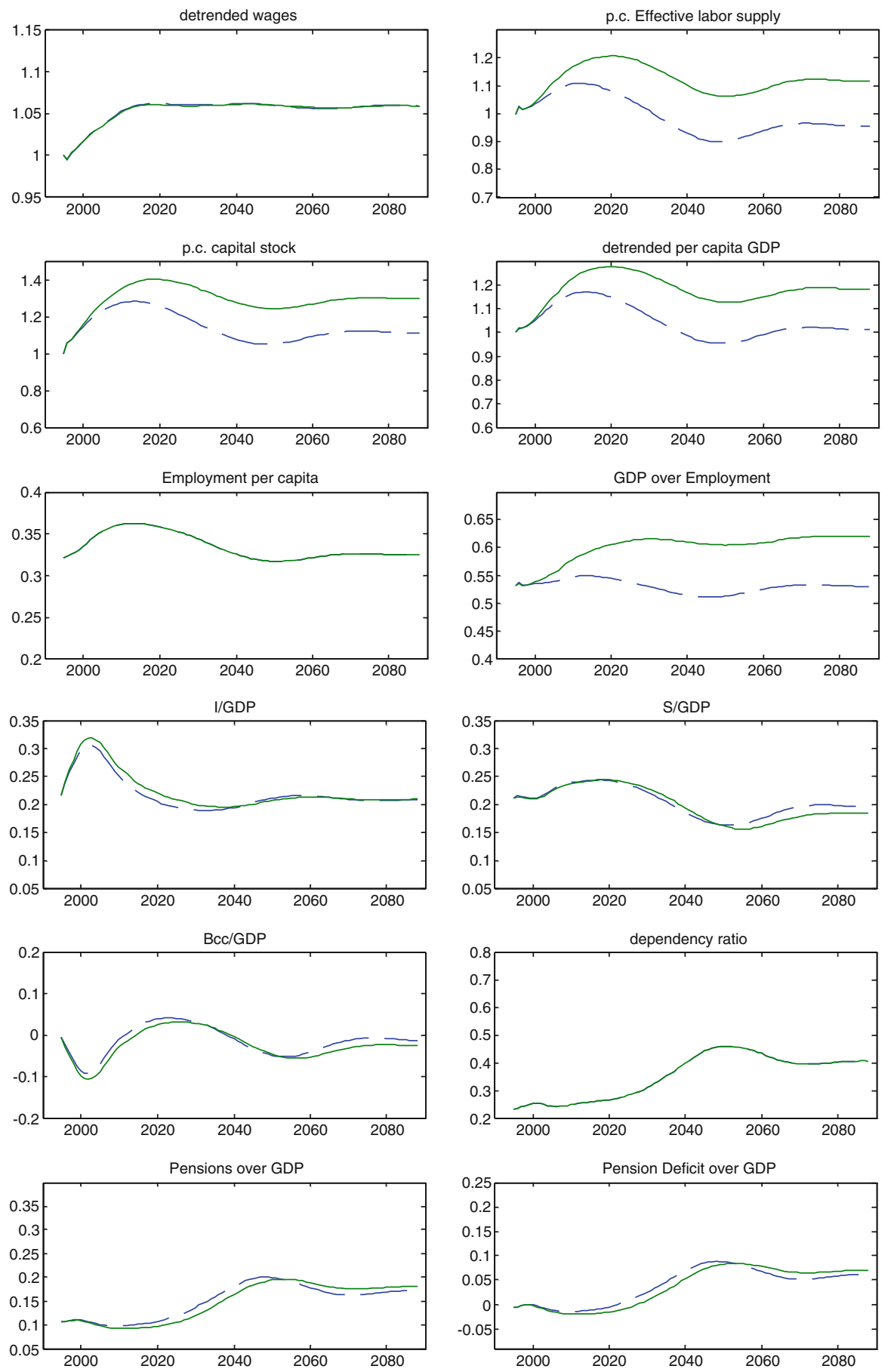

Fig. 6 Dashed lines: Scenario 1, solid lines: Scenario 5 
Open Access This article is distributed under the terms of the Creative Commons Attribution Noncommercial License which permits any noncommercial use, distribution, and reproduction in any medium, provided the original author(s) and source are credited.

\section{References}

Aparicio R, Tornos A (2000) La inmigración y la economía española. IMSERSO, Madrid Auerbach AJ, Kotlikoff LJ (1987) Dynamic fiscal policy. Cambridge University Press, Cambridge

Borjas G (1999) The economic analysis of immigration. In: Ashenfelter O, Card D (eds) Handbook of labour economics, vol 3A. North-Holland, Amsterdam

Bosca JE, Fernandez M, Taguas D (1999) Estructura Impositiva en los Paises de la OCDE. Ministerio de Economia

Burnside C, Eichenbaum M, Fisher M (2004) Fiscal shocks and their consequences. J Econ Theory 115:89_ 117

Canova F, Ravn M (2000) The macroeconomic effects of German unification: real adjustments and the welfare state. Rev Econ Dyn 3:423-460

Card D (2001) Immigrants inflows, native outflows, and the local labour market impacts of higher immigration. J Labour Econ 19(2):22-64

Catalunya C (2006) Informe Semestral I/2006. Economía española y contexto internacional

Christiano L, Eichebaum M, Evans CL (2005) Nominal rigidities and the dynamic effects of a shock to monetary policy. J Political Econ 113(1):1-45

Collado MD, Iturbe-Ormaetxe I, Valera G (2004) Quantifying the impact of immigration on the Spanish Welfare State. Int Tax Public Finance 11(3):335-353

Diaz-Gimenez J, Diaz-Saavedra J (2009) Delaying retirement in Spain. Rev Econ Dyn 12:147-167

Jimeno JF, Moral E, Saiz L (2006) Structural breaks in labor productivity growth: the United States vs. the European Union. Banco de España working paper 0625

Kara E, von Thadden L (2006) Monetary policy and demographic changes. European Central Bank, mimeo

Krueger D, Ludwig A (2006) On the consequences of demographic chenge for rates of returns to capital, and the distribution of wealth and welfare. J Monet Econ (forthcoming)

Oficina Económica del Presidente (2006) Inmigración y Economía Española

Ortega F (2007) Immigration, citizenship, and the size of goverment. Universitat Pompeu Fabra, mimeo

Ottaviano G, Peri G (2006) Rethinking the gains from immigration: theory and evidence from the US. NBER, working paper 11672

Razin A, Sadka E (1999b) Unskilled migration: a burden or a boom for the welfare state. NBER working paper 7013

Rojas J (2005) Life-cycle earnings, cohort size effects and social security: a quantitative exploration. J Public Econ 89:465-485

Storesletten K (2001) Sustaining fiscal policy through immigration. J Political Econ 108:300-323 